\title{
Development of polymer coating filled with anthropogenic waste for building structures protection
}

\author{
Oleg Selivanov ${ }^{1, *}$, Vladimir Chukhlanov ${ }^{1}$, and Marina Ilina $^{1}$ \\ ${ }^{1}$ Vladimir State University named after A.G. and N.G. Stoletovs, 600000, Vladimir, Russia
}

\begin{abstract}
The results of developing protective polymer coating characterized by high strength and containing galvanic waste are presented. This coating is designed to protect concrete and metal surfaces of various building structures against adverse natural and external impact. The coating is developed basing on polymethylphenylsiloxane binder, tetraisopropyltitanate hardener and anthropogenic waste - galvanic sludge used as the filler. The application of polymethylphenylsiloxane as a binder improves heat-resistant properties of the resulting coating and reduces its water absorption. Galvanic sludge in an amount of 5-15 wt. allows increasing the coating strength properties and reducing its cost, meanwhile solving another important issue - safe disposal of galvanic sludge.
\end{abstract}

\section{Introduction}

Currently, the polymer composite materials find wide application in the construction industry [1-3]. Their usage as protective coatings for concrete and metal surfaces of buildings and construction, structural elements against the effect of adverse natural factors, such as precipitation, ultraviolet radiation, acid rain, temperature exposure, etc. is of great interest. These materials provide good corrosion protection, strong adhesion to the surface, low water absorption, easy application and attractive external aesthetic appearance. The disadvantages of polymer protective coatings include low strength properties, loss of performance properties at the temperature above $+80^{\circ} \mathrm{C}$ and high cost. In this regard, protective coatings based on polyorganosiloxane binder or modified with polyorganosiloxanes are of great practical importance [4-5]. These coatings possess good heat resistance (up to $250^{\circ} \mathrm{C}$ ), low water absorption, resistance to oxidative degradation and solar radiation.

These coatings disadvantages also include poor physical and mechanical properties, in particular, strength, adhesion and high cost. The research objective is to develop inexpensive protective polyorganosiloxane coating characterized with good physical and mechanical properties. To reach this objective, it has been proposed to use calcined galvanic sludge - waste of galvanic production - as the filler for the protective polyorganosiloxal coating. At the same time, another important issue is solved - safe disposal of galvanic sludge [6-7].

*Corresponding author: selivanov6003@mail.ru 


\section{Materials and research methods}

Polymethylphenylsiloxane (PFMS) (GOST 15866-70) was used as a polymer binder to produce the coating. PFMS is a linear polysiloxane, in the Si-O-Si chain where each silicon atom has both phenyl and methyl group. Tetraisopropyltitanate (TU 2423-008-502847642006), the product of interaction of titanium tetrachloride and isopropyl alcohol, was used for the polymer composition curing.

Calcined galvanic sludge was used as the filler. Its introduction into the protective polyorganosiloxane material pursues two objectives:

- imparting good strength properties to the resulting protective coating;

- reducing the protective material cost by introducing cheap filler into the composition.

This filler was obtained by calcination of galvanic sludge, formed during chemical treatment of galvanic production effluents using calcium hydroxide at the temperature of $6500 \mathrm{C}$. The composition analysis of calcined galvanic sludge, carried out applying D8 powder diffractometer for advance (Germany), showed that heavy metals, making up the galvanic sludge, are mainly in the form of oxides. The oxide composition of calcined galvanic sludge is shown in table 1.

Table 1. The oxide composition of the calcined galvanic sludge.

\begin{tabular}{|c|c|}
\hline $\begin{array}{c}\text { Metal oxide in the calcined galvanic } \\
\text { sludge composition }\end{array}$ & Amount, \% wt. \\
\hline $\mathrm{ZnO}$ & 14.2 \\
$\mathrm{CuO}$ & 4.2 \\
$\mathrm{CaO}$ & 34.5 \\
$\mathrm{NiO}$ & 4.6 \\
$\mathrm{Fe}_{2} \mathrm{O}_{3}$ & 8.3 \\
$\mathrm{Cr}_{2} \mathrm{O}_{3}$ & 18.8 \\
$\mathrm{SiO}_{2}$ & 4.2 \\
\hline
\end{tabular}

The amount of zinc and chromium oxides is the largest. Thus, we can expect the strength increase of the developed protective coating when calcined galvanic sludge is used as the filler. The metal oxides such as nickel, chromium, zinc, and copper increase heat resistance and chemical resistance of the protective coating. In addition, the filler oxide components being a part of the protective composition contribute to the polymer structuring, making it possible to produce coatings with the improved continuity, adhesion, hardness and elasticity. Besides it is important that calcined galvanic sludge in the protective composition causes its filling with dispersed metal oxides, which produce stabilizing effect in the case of polyorganosiloxane coatings destruction at high temperatures, due to the blocking of the end silanol groups and macroradicals on the metal surface.

Calcined galvanic sludge is subjected to fine grinding in a ball mill. The resulting filler is of less than 40 microns grinding degree (according to GOST 6589-74). Figure 1 demonstrates the calcined galvanic sludge filler. 


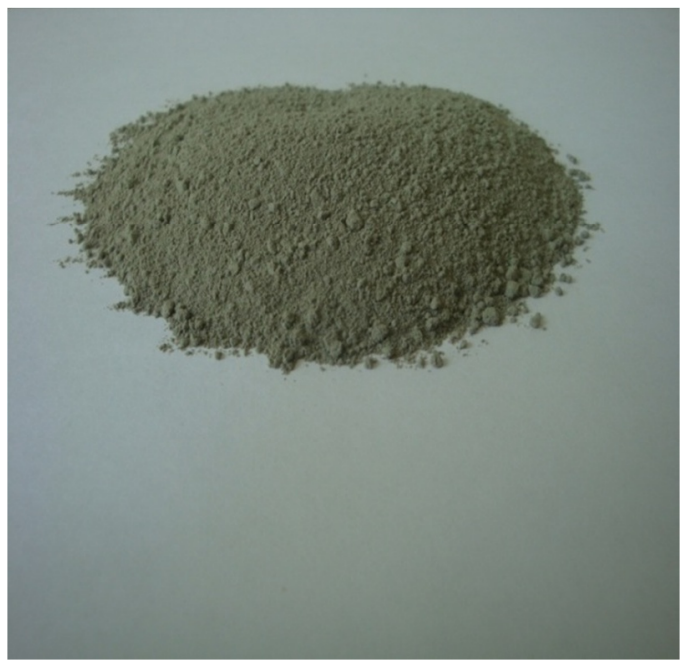

Fig. 1. Filler - calcined galvanic sludge.

The physical and mechanical characteristics of the resulting protective coating were determined applying the following methods: dynamic strength determination according to GOST 9.602-2016, coating adhesion by cross-cut test according to GOST 15140-78, tensile strength according to GOST 18299-72.

\section{Results and discussion}

Polymethylphenylsiloxane was selected as a polyorganosiloxane binder, for producing homogenized composition where filler is spread evenly over the entire depth of the resulting coating. Besides, polymethylphenylsiloxane increases heat resistance of the cured coating and reduces its water absorption.

Tetraisopropyltitanate, used as a hardener, causes the improvement of the coating strength and adhesive properties, which is associated with the formation of chemical bonds between polymethylphenylsiloxane and tetraisopropyltitanate due to the reactive groups in both the hardener and polymethylphenylsiloxane. In addition, tetraisopropyltitanate decomposition under the air moisture impact can cause the formation of nanoscale titanium oxide, which as an active filler is embedded in the polymer macromolecules structure and provides spatially cross-linked structure of the resulting coating, thus increasing its strength.

We have selected waste of electroplating - galvanic sludge as the filler. Depending on the composition and neutralization method, galvanic sludge refers to the 2-3 hazard class and is an anthropogenic waste. To reduce the galvanic sludge amount and involve it in recycling as a secondary raw material, currently the technologies are being developed for using galvanic sludge as a useful target additive in various construction materials [8-9].

In our research the protective coating samples were prepared on the basis of the following technology: tetraisopropyltitanate and calcined galvanic sludge were injected alternately into polymethylphenyloxane. The composition was thoroughly mixed and applied onto a metal substrate. Drying time was 24 hours at the temperature of $25^{\circ} \mathrm{C}$.

At the first research stage, the compositions were developed for producing protective coating samples based on the above technology. The compositions for producing polyorganosiloxane coating samples and their physical and chemical characteristics are presented in table 2 . 
Table 2. Compositions for producing samples of polyorganosiloxane coating and their physical and chemical characteristics.

\begin{tabular}{|c|c|c|c|c|c|c|}
\hline \multirow{2}{*}{$\begin{array}{c}\text { Sample } \\
\text { № }\end{array}$} & \multicolumn{3}{|c|}{ Composition, wt. } & \multicolumn{3}{c|}{ Coating physical and chemical characteristics } \\
\cline { 2 - 7 } & PFMS & TIPT & GS & $\begin{array}{c}\text { Coating } \\
\text { impact } \\
\text { strength, } \mathbf{N}^{*} \mathbf{m}\end{array}$ & $\begin{array}{c}\text { Coating } \\
\text { adhesion, point }\end{array}$ & $\begin{array}{c}\text { Tensile } \\
\text { strength, } \\
\text { kgf/cm }\end{array}$ \\
\hline 1 & 40 & 12 & 15 & 6 & 1 & 68 \\
\hline 2 & 25 & 5 & 10 & 7 & 1 & 73 \\
\hline 3 & 50 & 10 & 25 & 5 & 1 & 52 \\
\hline 4 & 15 & 8 & 40 & 4 & 1 & 48 \\
\hline 5 & 60 & 20 & 5 & 6 & 1 & 59 \\
\hline
\end{tabular}

The study has revealed that when the amount of calcined galvanic sludge in the composition is over 15 wt. coating adhesive and strength properties deteriorate, composition viscosity increases and the possibility of technological defects in the protective coating significantly increases. The introduction of calcined galvanic sludge of less than 5 wt. does not cause any significant increase of the coating strength.

To assess the strength properties of the developed protective coating, we have compared it with the known polyorganosiloxane coating, where polymethyldimethylphenylsiloxane resin mixture, modified with pentaphthalic resin and polymethylphenylsiloxane resin, organic solvent, hardener and the mixture of asbestos and mica, metal oxide and silicon carbide, was used as the binder [10].

The comparative characteristics of physical and mechanical properties of the known protective polyorganosiloxane coating and of the developed coating on the basis of the composition containing 25-40 wt. of polymethylphenylsiloxane, 5-12 wt. of tetraisopropyltitanate hardener and 5-15 wt. of calcined galvanic sludge filler are presented in table 3.

Table 3. Physical and mechanical characteristics of the known and developed protective coating.

\begin{tabular}{|c|c|c|c|}
\hline \multirow{2}{*}{ № } & Characteristics & \multicolumn{2}{|c|}{ Value } \\
\cline { 3 - 4 } & & Known & Developed \\
\hline 1 & Coating impact strength, $\mathrm{N} * \mathrm{~m}$ & 5 & $6-7$ \\
\hline 2 & Adhesion by cross-cut, point & 1 & 1 \\
\hline 3 & Tensile strength, $\mathrm{kgf} / \mathrm{cm}^{2}$ & 56 & $68-73$ \\
\hline
\end{tabular}

The table demonstrates that the developed protective coating reveals better impact strength and tensile strength than the known polyorganosiloxane coating, but adhesion to the coating corresponds to the known one.

Thus, the developed protective polymer coating provides good adhesion with the surface, technologically simple application, coating curing at room temperature, improved strength characteristics, low cost, due to the usage of calcined galvanic sludge, the solution of the safe disposal issue of man-made waste.

\section{References}

1. A. Berlin, S. Vol'fson, V. Oshmjan, N. Enikolopov, Principles of creation of composite polymeric materials (Chemistry, Moscow, 1990)

2. I. Vitkalova, A. Torlova, E. Pikalov, O. Selivanov, Advances in Intelligent Systems and Computing 983, 778-785 (2019) 
3. A. Torlova, I. Vitkalova, E. Pikalov, O. Selivanov, Advances in Intelligent Systems and Computing 1116, 544-551 (2020)

4. V. Chukhlanov, O. Selivanov, N. Chukhlanova, Polymer Science Series D 11(2), 165168 (2018)

5. V. Chukhlanov, O. Selivanov, Russian Physics Journal 59(7), 944-948 (2016)

6. I. Vitkalova, A. Torlova, E. Pikalov, O. Selivanov, Advances in Intelligent Systems and Computing 983, 786-794 (2019)

7. K. Perovskaya, D. Petrina, E. Pikalov, O. Selivanov, E3S Web of Conferences 91, 04007 (2018) doi.org/10.1051/e3sconf/20199104007

8. I. Vitkalova, A. Torlova, E. Pikalov, O. Selivanov, MATEC Web of Conferences 193, 03035 (2018) doi.org/10.1051/matecconf/201819303035

9. I. Vitkalova, A. Torlova, E. Pikalov, O. Selivanov, E3S Web of Conferences 33, 02062 (2018) doi.org/10.1051/e3sconf/20183302062

10. Russian patent No 2216567 (2003) 